\title{
ORDENACIÓN Y GESTIÓN DE RECURSOS HÍDRICOS EN UN ÁMBITO SUBÁRIDO: EL ABASTECIMIENTO DE LOS MUNICIPIOS INTEGRADOS EN LA MANCOMUNIDAD DE LOS CANALES DEL TAIBILLA
}

\author{
Fernando Vera Rebollo \\ Alfredo Morales Gil
}

\begin{abstract}
RESUMEN
El agua es, sin lugar a dudas, el motor impulsor del desarrollo socioeconómico de las tierras del sureste peninsular ibérico; pero su escasez ha impuesto tradicionalmente una utilización razonada del recurso, al tiempo que se aseguraba su uso fuera de los espacios próximos a los cauces naturales, para lo que se hacía necesaria la construcción de una gran red de distribución. Con la creación de la Mancomunidad de los Canales del Taibilla cristaliza la vieja aspiración de garantizar el abastecimiento de núcleos urbanos y entidades estatales. Es así como se sientan las bases que impulsarían el desarrollo industrial, a partir del decenio de los cincuenta y, desde los años sesenta, el despegue de la actividad turística en el litoral. Los resultados conseguidos merced a este sistema de abastecimiento son evidentes, pero el actual ritmo de desarrollo urbano y demográfico de las principales ciudades y la nueva etapa expansionista que vive la franja litoral han puesto de relieve las limitaciones del Organismo, condicionado por la disponibilidad de recursos, por lo que este trabajo trata de esclarecer su situación actual y perspectivas de futuro.
\end{abstract}

PALABRAS CLAVE: Recursos hídricos, sistema de abastecimiento público de aguas, usos y competencias, desarrollo regional.

\section{RÉSUMÉ}

L'eau constitue, sans aucun doute, la force motrice du développement socio-économique du sol dans le sud-est de la Péninsule Ibérique. Il s'imposait une utilisation rationnelle de cette faible ressource, et il fallait en même temps s'assurer de son utilisation en dehors des espaces proches des cours naturels. Pour cela il était nécessaire de construire un grand réseau de distribution qui, dans le cas qui nous concerne, a trois piliers fondamentaux: les réseaux de distribution traditionnels des ressources locales; les canaux d'approvisionnement des zones urbaines, industrielles et touristiques, qui furent commencés en 
1950 avec la "Mancomunidad de los Canales del Taibilla"; et, en fin, des infrastructures de distribution des eaux du "Trasvase Tajo-Segura". Le second pilier est celui qui a eu le plus de répercussions et, cependant, c'est le moins connu et celui qui inquiète le plus à présent. Voilà le motif pour lequel il a attiré notre attention, de manière que cette étude essaie d'éclairer sa situation actuelle et ses perspectives de futur.

Las tierras del sureste peninsular, por su ubicación, se inscriben en un medio natural cuyos componentes las hacen merecedoras de una ocupación humana para asentarse en ellas, como se ha podido comprobar desde la prehistoria. Los factores medio ambientales, aunque han planteado problemas a las sociedades humanas que ocupan este ámbito, ya que, como tendremos ocasión de ver, el agua define el potencial ecológico para el desarrollo de las actividades económicas, han sido favorecedores de un desarrollo socioeconómico, en relación con dos realidades de la propia configuración física.

En primer lugar, la estructuración de los relieves bélicos en su tramo oriental peninsular que los compartimentan en una serie de valles paralelos, dispuestos con dirección SW-NE, separados entre sí por una elevaciones montañosas de modesta altitud -pocas veces se superan los $1.000 \mathrm{~m}$ - que están comunicados entre ellos por unas depresiones transversales que facilitan las relaciones. A este respecto cabría citar la Depresión Prelitoral Murciana y las fosas transversales del Vinalopó y Segura. De esta forma, todo el territorio queda enlazado por el SW con Andalucía y por el NE con la parte central de la Comunidad Valenciana, final del corredor mediterráneo que la comunica con el Midi francés. Por otro lado, el origen mesozoico de los materiales que constituyen las principales unidades de relieve y los aportes recientes debidos a la geodinámica externa, hacen de sus suelos unos de los de mayor potencial productivo.

En segundo lugar hay que señalar la benignidad de su clima, sobre todo en invierno, cuando las temperaturas mínimas en la costa y en los valles corredores próximos a ella no suelen descender de los $0^{\circ}$. De forma que SC pueden practicar cultivos hasta en esta estación. Esta condición tan favorable está ligada a la primera, ya que es la disposición del relieve frente a la circulación atmosférica general la que los convierte en obstáculos frente a las masas de aire frío descendentes del N, transformándolos en grandes pantallas. Pero si este hecho resulta favorable para el comportamiento térmico, no lo es respecto de las precipitaciones, ya que quedan retenidas en las fachadas de barlovento y no llegan a estas comarcas, caracterizadas por una marcada indigencia pluviométrica.

A tenor de estos componentes físicos, nos encontramos con un territorio con unas condiciones óptimas para el desarrollo socioeconómico, basado en su situación de encrucijada de caminos, en el potencial de uso agrícola de los suelos y en un litoral estructurado alternando áreas de playas con acantilados, lo que justifica el interés de la actividad turística. Ahora bien, toda esta realidad sólo es viable si se cuenta con el agua suficiente para asegurar los cultivos y los desarrollos urbanos, industriales y turísticos.

Tradicionalmente este problema se resolvió aprovechando las escasas aguas epigeas, destacando fundamentalmente el aprovechamiento de los caudales alóctonos del río Segura y, en menor medida, los del Vinalopó, junto a los de algunas fuentes. Pero desde la década de los años cincuenta tales recursos se han mostrado insuficientes y se ha tenido que recu- 
rrir a la explotación de las reservas hipógeas autóctonas, que en la actualidad están llegando a su fin, imponiéndose una racionalización de la explotación. En definitiva, todo el territorio del SE peninsular se ve necesitado de las aportaciones de caudales foráneos para poder asegurar su futuro y así se procedió en 1968 al iniciarse la obra del trasvase del Tajo al Segura.

Si el agua es, sin lugar a dudas, el motor impulsor del desarrollo socioeconómico de estas tierras, lógicamente se imponía una utilización razonada del recurso, al tiempo que se asegurase su uso fuera de los espacios próximos a los cauces naturales. Para ello era necesaria la construcción de una gran red de distribución que, en el caso que nos ocupa, tiene tres pilares fundamentales: redes de distribución tradicionales de los recursos locales; canales de abastecimiento de zonas urbanas, industriales y turísticas, que se empezó a hacer en 1950, con la Mancomunidad de los Canales del Taibilla, y finalmente, infraestructuras de distribución de las aguas del trasvase Tajo-Segura. La segunda es la que más trascendencia ha tenido y, sin embargo, es la menos conocida y la que hoy día más preocupa, ya que son notables los problemas que se producen por falta de suministros, sobre todo en el litoral; de ahí que haya atraído nuestra atención, por lo que en este trabajo se trata de esclarecer su situación actual.

La Mancomunidad de los Canales del Taibilla es un ejemplo de sistema de abastecimiento público de aguas, de dimensión espacial suprarregional (afecta a las comunidades autónomas de Valencia, Murcia y Castilla-La Mancha), que muestra la relación entre la dinámica demográfica y económica y la disponibilidad de caudales. Su funcionamiento, como organismo autónomo adscrito al MOPU, a través de la Dirección General de Obras Hidráulicas, define las funciones relativas a:

1. Estudios, planes y proyectos para abastecimiento de aguas a los 73 municipios correspondientes a las provincias de Murcia, Alicante y Albacete, a los que se unen 8 entidades (militares, portuarias o empresas estatales). En total, representan el abastecimiento de 1.600 .000 habitantes permanentes y algo más de 2 millones en los meses de verano, con un consumo medio de 209 litros por habitante y día, aunque son notables los contrastes entre distintos tipos de municipios, de acuerdo con la correlación existente entre consumo y nivel de vida, y en dependencia de la técnica y eficacia de la gestión en el tratamiento de los recursos.

2. Obras e instalaciones de captación, regulación, conducción, tratamiento y depósito.

3. Explotación de los aprovechamientos destinados al abastecimiento de aguas, cuya sistemática se fundamenta en una red básica de canales principales y de depósitos reguladores.

Este sistema es la palanca motriz del proceso de desarrollo urbano y demográfico del SE peninsular, que arranca en el decenio de 1950 y que vuelve a acelerarse en su zona costera desde 1985, cuando se inicia un nuevo proceso de desarrollo, vinculado a la actividad turística, en el litoral mediterráneo español. No obstante, las perspectivas de futuro son preocupantes, si se atiende al ritmo de crecimiento de nuevos asentamientos urbano-turísticos, ya que los recursos son limitados y cada vez es mayor la dependencia respecto a los volúmenes del trasvase Tajo-Segura, con los consiguientes conflictos entre comunidades autónomas con modelos y niveles de desarrollo contrapuestos, y entre grupos de usuarios dentro de un mismo espacio, que llevan a enfrentar la expansión del turismo con el futuro 
de la agricultura de regadío. Se perfila pues como un problema de desajustes entre necesidades y recursos, que no puede desprenderse de su contexto ecológico y técnico ${ }^{1}$.

\section{Del abastecimiento tradicional a la gestión mancomunada de los recursos}

La profunda transformación del modelo económico-territorial que se inicia en el decenio de los años 1960, asociada en nuestro ámbito al nivel de industrialización y, sobre todo, a la progresión de la actividad turística, supone la pérdida del carácter privilegiado del agua en la agricultura, frente a la demanda urbana, cuyo incremento ha sido constante.

En una primera etapa, hasta dicho decenio, el abastecimiento tradicional, mediante captaciones realizadas por los ayuntamientos o por los promotores de urbanizaciones turísticas, garantizó la cuantía del suministro y calidad de las aguas, en relación con un ritmo moderado en el crecimiento de la actividad turística, frente a la mayor progresión que se registraba en el litoral norte de la provincia de Alicante, esencialmente en el núcleo de Benidorm. De hecho, en esta primera etapa no pertenecían a la Mancomunidad del Taibilla (MCT) algunos de los municipios que actualmente se sitúan a la cabeza de la demanda, como es el caso de Torrevieja. Los mayores niveles de gasto correspondían a las tres ciudades más importantes, Murcia, Alicante y Cartagena, seguidas por núcleos urbanos alejados de la costa y, habitualmente, con una notable dedicación a las actividades industriales: Elche, Molina del Segura, Crevillente y Lorca. Aún en 1976, el abastecimiento de las tres primeras ciudades citadas representaba el 53\% del total suministrado por la MCT, a pesar de que los núcleos de mayor envergadura siempre han contado con alguna fuente complementaria de recursos (en Alicante y Elche se trata de pozos, mientras que en Murcia son las propias aguas del río Segura). No obstante, como se verá en adelante, el papel de lo que otrora fueron fuentes alternativas ha perdido peso, hasta el punto de que la MCT suministra más del $80 \%$ del total consumido.

Las actividades de ocio producen el despegue del gasto de agua en el decenio de los setenta en los municipios litorales, en concomitancia con el crecimiento de los efectivos demográficos $\mathrm{y}$, estacionalmente, en respuesta al elevado número de viviendas turísticas y de segunda residencia. Lo que en principio no parecía más que un incremento durante el período estival, desbordó las previsiones, motivando un conflicto de falta de recursos en municipios que habían dependido tradicionalmente para su abastecimiento de la explotación de los acuíferos hipogeos locales. Por tanto, con la intención de garantizar el suministro y, al tiempo, de contar con la seguridad de un sistema de abastecimiento que abría unas perspectivas favorables al proceso de urbanización, se integran nuevos ayuntamientos en la MCT, como es el de Torrevieja (1972), hecho que trajo consigo un impulso extraordinario de la construcción, pasando de 230 edificaciones de nueva planta en 1971, a 1.136 al siguiente año. Mientras tanto, en otros ayuntamientos que ya formaban parte de la MCT, se construyen las infraestructuras necesarias, que favorecen un disparo extraordinario del consumo y, por ende, del proceso de construcción. Se puede afirmar que el agua ha sido el principal

1 BETHEMONT, J., Geografia de la utilización de las aguas continentales, Barcelona, OikosTau, 1980, pp. $49-50$. 
condicionante del despegue turístico en el SE peninsular, con mayor influencia que la disponibilidad de suelo o de capitales. La mejor prueba es que, una vez garantizado el suministro, las inversiones en promoción y construcción inmobiliaria han sido espectaculares.

Pero ya desde comienzos del citado decenio de los setenta, la MCT estableció las previsiones sobre necesidades futuras, a través de una ampliación de los abastecimientos, en cuyo proyecto se fijaron los máximos previstos de población y consumo. De ellos interesa señalar el establecimiento de una dotación teórica, afectada de un coeficiente de mayoración, en atención al nivel de vida, quedando las dotaciones-tipo como sigue:

\begin{tabular}{|c|c|c|}
\hline Poblaciones & nferiores a $1.000 \mathrm{~h}$. & 100 litros/h/día \\
\hline “6 & entre $1.000-6.000 \mathrm{~h}$ & 150 litros/h/día \\
\hline “6 & $6.000-12000 \mathrm{~h}$ & 175 litros/h/día \\
\hline " & $12.000-50.000 \mathrm{~h}$. & 200 litros/h/día \\
\hline " & mayores $50.000 \mathrm{~h}$. & 235-275/1./h/día \\
\hline
\end{tabular}

Es de notar que en los núcleos mayores de 50.000 habitantes, las necesidades públicas canalizan en torno al 6\% del agua facturada. Aunque en esta fijación de dotaciones teóricas no aparece un problema de mayor envergadura, cual es el abastecimiento de núcleos turísticos, cuyos parámetros de consumo distan considerablemente de los habituales en el suministro urbano convencional. En efecto, los distintos hábitos de consumo, tendentes al despilfarro, junto con el riego de jardines privados, llenado de piscinas y otros elementos de consumo, como son parques acuáticos y de atracciones, desbordan las previsiones e introducen un factor conflictivo en la gestión de los recursos. No obstante, en situaciones críticas, la imposición de restricciones, mediante cortes periódicos en el suministro, genera hábitos en el consumo de agua. Del mismo modo, la contracción del consumo puede venir por la vía del alza de tarifas. En todo caso, el verdadero problema ha surgido a raíz del nuevo despegue turístico, desde 1985, puesto que no se trata sólo de racionalizar el consumo, sino de abastecer a municipios que, en apenas cuatro años, han duplicado su población y viviendas.

\section{Los recursos}

El análisis retrospectivo y actual de las aportaciones de agua pone de manifiesto un proceso de dependencia creciente respecto a los volúmenes del trasvase Tajo-Segura, es decir, recursos alóctonos que condicionan el futuro. Desde 1945, fecha en que se inician los abastecimientos y hasta los años 1960, las aportaciones del río Taibilla fueron suficientes, con un volumen máximo anual de $47 \mathrm{Hm}^{3}$. Pero el fuerte desarrollo económico que se iniciaba motiva el disparo de la demanda, junto con la ampliación del número de municipios 
mancomunados, para lo que se recurre a caudales procedentes de pozos y manantiales, explotando al máximo las infraestructuras existentes y, por primera vez, se utilizan aguas del propio río Segura (año 1964), con lo que se inicia un largo conflicto de competencias sectoriales entre usuarios, extraordinariamente grave en la actualidad.

Fue en la segunda mitad de los sesenta cuando la alarmante situación de sequía que padecía el SE y los intereses que existían en torno a la ampliación del regadío y, más aún, al desarrollo turístico y de la construcción, propiciaron el inicio de las obras del polémico trasvase del Tajo al Segura ${ }^{2}$. Así, la MCT prevé la primera gran ampliación de suministros contando con los recursos del trasvase, que se cifraban en $155 \mathrm{Hm}^{3} /$ año, según el déficit calculado; para ello se ampliaban los canales y se iniciaba la construcción de depósitos y depuradoras. Este nuevo esquema de canales duplicaba las instalaciones existentes, afectando esencialmente a Murcia, Alicante y Cartagena; pero, lo más interesante, desde nuestro punto de vista, es que suponía la garantía del abastecimiento para la zona costera entre Alicante y Cartagena. Pero los recursos tardaban en llegar, en tanto proseguía, a lo largo de la primera mitad de los años setenta, la incorporación de municipios a la MCT, de manera que los caudales resultaban insuficientes para mantener los mínimos exigibles en las poblaciones abastecidas.

Es ya en 1978 cuando comienzan las aportaciones del trasvase, que van increméntandose progresivamente hasta 1987. De tal manera que sólo en el caso de la provincia de Alicante, en 1984, de los 45' $743 \mathrm{Hm}^{3}$ aportados, el trasvase supone el 89' $42 \%$ del total de las aguas. Mientras tanto y para el conjunto de la MCT, en 1987, el trasvase facturó al organismo un total de 118'18 $\mathrm{Hm}^{3}$. Por tanto, si se tiene en cuenta que la dotación del trasvase establecida para suministro poblacional está fijada, en su primera fase, en un máximo de $110 \mathrm{Hm}^{3} / a n ̃ o$, se comprende que, de no aumentar las aportaciones del Taibilla o de recursos complementarios -hecho muy poco probable- se ha tocado techo en las disponibilidades de recursos. Es de notar el fuerte incremento de los consumos en relación a 1986, año en el que los volúmenes de agua del trasvase Tajo-Segura facturados a la MCT sumaron 106' $55 \mathrm{Hm}^{3}$; un crecimiento que llevó al organismo a hacer "una llamada de atención acerca de los problemas que podrían presentarse en un futuro muy próximo, caso de no disponer de recursos adicionales a los ya mencionados"3. Por tanto, superada la dotación del trasvase (la Memoria indica que únicamente las menores pérdidas habidas a lo largo del trasvase permitieron el incremento mencionado), es evidente que las actuales disponibilidades de recursos de la MCT son insuficientes para atender la creciente demanda de los núcleos mancomunados ${ }^{4}$. Esta situación contrasta con el anteriormente citado despegue de la promoción y construcción inmobiliaria, en relación con la actividad turística en la franja litoral, y con las nuevas formas de organización y cualificación del espacio turístico, asociadas al agua. A tenor de ello conviene tener en consideración la reciente integración del municipio de Aguilas, que contará con suministro dentro del año 1989, con lo que queda completado el abastecimiento del litoral murciano.

2 MORALES GIL, A. Y JUÁREZ SÁNCHEZ-RUBIO, C., "Cambios del uso del agua”, Estudios geográficos, $\mathrm{n}^{\circ} 165,1981$.

3 MOPU, Mancomunidad de los Canales del Taibilla, 1986, Madrid, Secretaría General Técnica, 1987.

4 MOPU, Mancomunidad de los Canales del Taibilla, 1987, Madrid, Secretaría General Técnica, 1988. 


\section{La expansión de la demanda: situación actual y perspectivas}

Si se atiende a la evolución de la utilización de agua del conjunto de la MCT se comprueba un incremento constante, aunque el ritmo de consumo varía sensiblemente en relación con la diferente tipología de núcleos integrados. Por tanto, el análisis de la demanda cobra verdadero significado cuando se estudian las tendencias de gasto en municipios rurales, industriales, turísticos y áreas urbanas. Es así como se entiende el contraste entre el disparo del consumo en la franja costera y el estancamiento de los municipios interiores; de manera que las áreas de mayor nivel de consumo coinciden con las de más riqueza y trascendencia económica en la actualidad, dependientes en buena parte del desarrollo de la actividad turística, cuyos efectos en la estructura económica (contribución al VAB) y territorial (eclosión de nuevas comunidades, expansión urbana) son notables entre la capital alicantina y Mazarrón.

La interpretación de este esquema corresponde a unas condiciones naturales contrastadas en el espacio de la MCT y, por ende, a un diferente potencial de uso, hasta el punto de que los contrastes en cuanto al nivel de gasto, a lo que desde el punto de vista del desarrollo regional se interpreta como verdaderos desequilibrios, parten de diferencias económicas concretadas en productividad y empleo. De estas dos variables se desprenden notables divergencias en otros componentes, que atañen a la cuestión demográfica, así como a los niveles de vida y dotaciones de infraestructura y equipamiento.

No obstante, al margen de la consideración de las disparidades, el problema se plantea cuando se entiende que el agua es en el ámbito de la MCT, por sus condiciones naturales, el recurso básico afectado al desarrollo regional; un recurso limitante, en atención a su origen y al ritmo de consumo de los últimos cinco años, que hacen prever que el freno al crecimiento actual se presentará de una forma inevitable, si no se cuenta con nuevos recursos.

A ello contribuye eficazmente el sistema de utilización del agua en el espacio turístico del litoral mediterráneo español, que no sólo impide renunciar a los modos de consumo que implican un despilfarro excesivo, sino que la tendencia apunta a un incremento del gasto en los asentamientos turístico-residenciales, ante las nuevas formas de venta del producto turístico ${ }^{5}$. Una situación que puede agravarse en el caso de que no se consigan nuevos recursos o no se incrementen las dotaciones actuales y que reafirmará los contrastes regionales en cuanto a productividad, traducidos en mayores desequilibrios, puesto que no hay que olvidar que el sistema de aprovechamiento turístico del litoral -basado en el sol y las playas- no puede ser transferido a un espacio interior.

El cuadro I, en el que se recogen los municipios con mayor gasto de agua dentro de la $\mathrm{MCT}$, muestra el peso del consumo en relación con la susomentada tipología de núcleos y, dentro de ella, con los que presentan la mayor dinámica demográfica y económica. Así, los mayores niveles de suministro corresponden a espacios urbanos definidos por unas funciones administrativas y de servicios propias de su misma entidad: Murcia y Alicante esencialmente. Un segundo grupo de grandes consumidores lo integran ciudades con rango de capital comarcal o subregional que concentran importantes dotaciones de servicios, en combinación

5 MARCHENA GÓMEZ, M. “Agua y turismo en la Andalucía Mediterránea”, ap. Demanda y economía del agua en España, Alicante, Caja del Mediterráneo y Diputación Provincial, 1987. 
Cuadro I

RELACIÓN DE LOS MUNICIPIOS DE LA MANCOMUNIDAD CON MAYOR CONSUMO (1987)

\begin{tabular}{|c|c|c|c|c|}
\hline MUNICIPIO & $\begin{array}{l}\text { CONSUMO } \\
\text { FACTURADO }\left(\mathbf{m}^{3}\right)\end{array}$ & $\begin{array}{l}\text { POBLACIÓN DE } \\
\text { HECHO (1986) }\end{array}$ & $\begin{array}{l}\text { \% SOBRE } \\
\text { de consumo }\end{array}$ & $\begin{array}{l}\text { L TOTAL } \\
\text { de poblacion }\end{array}$ \\
\hline Murcia (*) & 35.831 .633 & 309.504 & 21,4 & 19,5 \\
\hline Cartagena (1) & 39.383 .762 & 168.809 & 18,2 & 10,6 \\
\hline Alicante $(*)$ & 25.882 .878 & 265.543 & 15,5 & 16,7 \\
\hline Elche $(*)$ & 14.186.299 & 173.392 & 8,5 & 10,9 \\
\hline Lorca & 6.742 .232 & 66.880 & 4,0 & 4,2 \\
\hline Orihuela & 5.484 .223 & 52.400 & 3,2 & 3,3 \\
\hline Molina & 4.700 .403 & 34.913 & 2,8 & 2,2 \\
\hline Torrevieja (2) & 4.108 .002 & 18.454 & 2,4 & 1,1 \\
\hline Total & 127.319 .432 & 1.089 .895 & 76,5 & 68,7 \\
\hline
\end{tabular}

Fuente: Mancomunidad de los Canales del Taibilla y Censos de Población. ELABORACIÓN PROPIA.

(1) Integra al municipio de Cartagena y a las siguientes entidades del mismo: Base Naval, E.N. Bazán, REPESA, E.N. de Fertilizantes y Junta de Obras del Puerto. Las entidades representan el $28 \%$ del abastecimiento total del término.

(2) Se debe considerar la población flotante, que en verano alcanza los 160.000 habitantes.

(*) Integra el agua extraída de la MCT, con porcentajes que oscilan entre el 10 y el $13 \%$ del total. Nota: Los datos de consumo hacen referencia a 1987.

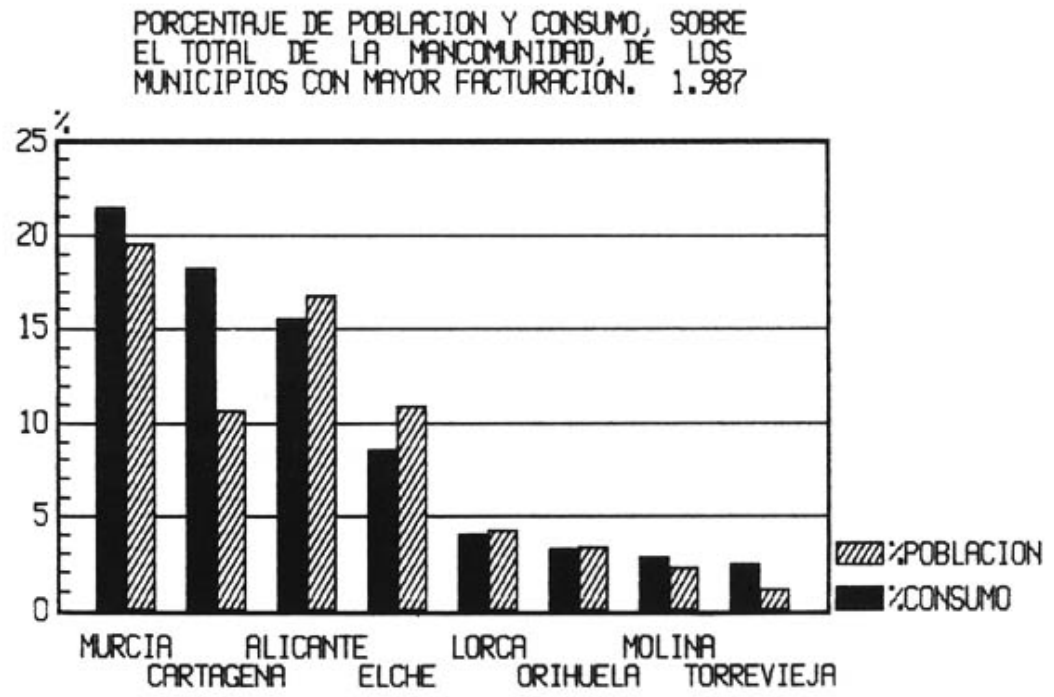


con la actividad industrial, que puede repercutir en diverso grado en la productividad y en el empleo; aparecen casos como el de Elche y Cartagena, en los que dicha función mantiene una importante contribución al PIB, junto a otros como Lorca y Orihuela, mejor definidos por su estructura de centros de servicios en una comarca rural.

Hasta este grupo se puede interpretar una relación lógica entre potencial demográfico y económico y uso de agua. Pero la distorsión comienza al aparecer entre los mayores demandantes dos municipios en los que la relación población-consumo no guarda lógica aparente. Se trata de Molina del Segura y Torrevieja, en los que influyen dos variables básicas, la industria y la actividad turística respectivamente, para interpretar el desarrollo regional y la desproporción citada. En el primer caso, el elevado nivel de gasto responde a la utilización de agua en las industrias conserveras y químicas, que justifican el extraordinario crecimiento de esta ciudad en la Vega del Segura. Mientras que en Torrevieja, la clave interpretativa reside en el despegue exorbitante del turismo residencial, con la consiguiente expansión de los asentamientos.

A tenor del diferente comportamiento en cuanto al gasto de agua, conviene analizar esta tipología, con la finalidad de conocer la situación actual y prever las tendencias que se proyectan hacia el futuro.

\subsection{El disparo del consumo de agua en los municipios turísticos}

El problema de este tipo de núcleos urbanos se asocia habitualmente con el que deriva específicamente de la desproporción entre el nivel de consumo durante la mayor parte del año y el disparo de la demanda que se produce en estío, época clave de la afluencia de visitantes. De ahí deriva tanto la necesidad de prever un incremento del gasto, que llega incluso a duplicar al registrado en el centro del invierno y, por ende, del establecimiento de previsiones en cuanto a recursos, como en lo que respecta a actuaciones en materia de infraestructura, cuya subutilización es manifiesta durante ocho o más meses al año. No obstante, al margen de la necesidad de tener muy en cuenta tales planteamientos, el problema que ahora se plantea se centra en la progresión del consumo que se produce en la franja litoral en los últimos años y, además, en los niveles de gasto que tipifican los asentamientos turísticos, inherentes, como se ha indicado, a las nuevas formas de promoción y venta del producto turístico. Es decir, no sólo se trata de un suministro que se dispara en proporción al crecimiento urbanístico del municipio turístico, sino que el gasto medio por habitante y día tiende a incrementarse en las denominadas urbanizaciones turísticas, donde el agua constituye un elemento esencial de atracción.

Bajo el común denominador del elevado gasto estacional y una progresión sorprendente en los últimos diez años, el peso de los municipios turísticos se ha dejado notar en el volumen total facturado por la MCT. Hay que señalar que el ya citado núcleo de Torrevieja representa sólo el 1'1 \% de la población total abastecida por la Mancomunidad, pero alcanza el 2 ' $4 \%$ del consumo global. Pero no se trata de un consumo propio del hecho urbano convencional; entre otros motivos porque la nota dominante en los siete municipios con mayor grado de dedicación turística es la irrupción reciente y novedosa de la vida urbana. En efecto, Torrevieja, Santa Pola, Guardamar del Segura, San Pedro del Pinatar, San Javier, Mazarrón y Los Alcázares, experimentan un despegue reciente, pasando de ser pequeños núcleos de 


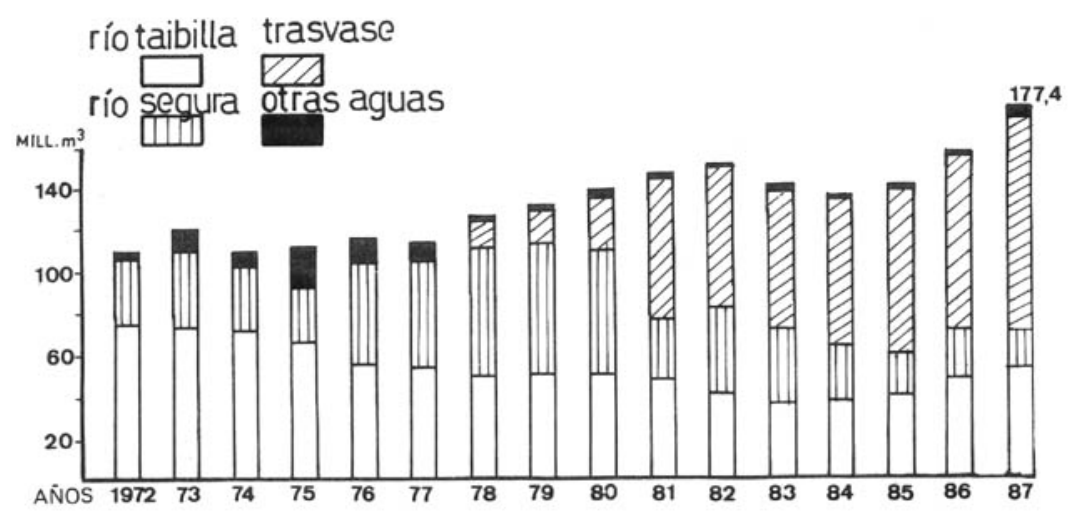

base primaria, con actividades consideradas tradicionales (agricultura, pesca, explotación salinera), a compactos seudourbanos, fruto de la expansión sin precedentes del uso residencial, inherente a la construcción de alojamientos turísticos, en un proceso que se desarrolla en forma de ensanches que prolongan el continuo urbano y mediante la consolidación de un nuevo sistema de asentamientos, que han llegado a configurar una nueva estructura territorial y urbanística.

El crecimiento de estos municipios (Los Alcázares alcanza la autonomía municipal en virtud de este proceso) ha sorprendido e invalidado todas las previsiones. Pero lo más conflictivo es que el ritmo progresa y se ha llegado al límite de los recursos disponibles. Desde 1985, fecha en que se inicia el segundo "boom" turístico, algunos de los municipios litorales integrados en la MCT han duplicado su número de unidades de vivienda. El mayor crecimiento corresponde a Torrevieja, municipio de $61^{\prime} 4 \mathrm{Km}^{2}$ de extensión y una población censal de 20.000 habitantes, que pasa de tener 19.000 viviendas en 1981 (15.000 eran de uso turístico y segunda residencia) a más de 30.000 en 1987, de las que unas 25.000 son de uso turístico y segunda residencia, mientras que el suelo urbano suma 1.400 Has y el total de suelo calificado por el planeamiento alcanza las 1.951 Has. La MCT, que suministra el $87 \%$ del agua que se consume en el municipio (el resto es de pozos municipales), aportó en 1984 un total de $2.511 .207 \mathrm{~m}^{3}$, mientras que en 1987 la cantidad total ascendió $4.108 .002 \mathrm{~m}^{3} .^{6}$

Un crecimiento similar de las aportaciones se produce en Guardamar del Segura, que pasa de 741.498 m, a 971.203 y, en la provincia de Murcia, en el municipio de San Javier, de

6 MORALES GIL, A. y VERA REBOLLO, J. F., La Mancomunidad de los Canales del Taibilla: sistema de abastecimiento público de aguas y factor de desarrollo económico-territorial, Alicante, Instituto Universitario de Geografía (en preparación). 
2.209.224 $\mathrm{m}^{3}$ facturados en 1984 a 3.475.986 en 1987. Aunque esta tendencia es común al resto de municipios con dedicación turística, si bien en los casos de Alicante y Cartagena, donde la actividad turística no es la predominante, influyen otras variables, tales como la industria y el propio rango de la entidad urbana, entendida como centro de servicios. Ello no excluye la consideración del potencial de alojamiento de la Playa de San Juan y de La Albufereta, en Alicante, y de un importante sector de La Manga del Mar Menor y entidades ribereñas (Los Nietos, Los Urrutias, Cabo de Palos) en el municipio de Cartagena.

\subsection{Incremento del consumo en áreas urbanas y núcleos industriales}

La relación entre la industrialización y el hecho urbano no es en este ámbito tan evidente, puesto que, como ya se indicó, aparecen espacios urbanos definidos por la prestación de servicios propios de su entidad y sin un peso relevante de las implantaciones fabriles. Tanto es así que con la excepción de Cartagena y, en menor medida, Elche, las ciudades con mayor gasto de agua son capitales de distinto rango, desde el autonómico al provincial, subregional y comarcal: Murcia, Alicante, Lorca y Orihuela. La evolución seguida por cada uno de estos municipios en cuanto al gasto de agua y las tendencias detectadas dependen de la base productiva y de la forma en que ésta se articula en el desarrollo regional.

Una primera aproximación al tema viene dada por la relación entre consumo de agua y población; de este modo se distinguen dos situaciones, en dependencia de que el porcentaje de población del municipio sea superior o inferior al del consumo de agua. Se entiende como normal para un núcleo urbano que estos porcentajes sean similares o que el de población sobrepase ligeramente al de gasto de agua. Así aparecen Alicante, Elche, Lorca y Orihuela: pero no ocurre igual en Cartagena, Murcia y Molina del Segura, hecho que se justifica en atención a diferentes factores estructurales.

En el caso concreto del municipio de Cartagena resulta obligado establecer algunas consideraciones previas que justifican la diferencia tan notable entre población y consumo y que derivan de la inclusión del núcleo urbano, las pedanías del campo y el espacio turístico de La Manga, la Base Naval, la Junta de Obras del Puerto y las entidades industriales con elevados consumos: E.N. Bazán, ENPETROL y E.N. de Fertilizantes. En conjunto, las entidades militares e industriales representan el 28 '7\% del abastecimiento total del término municipal. Así, el gasto de agua correspondiente a la Base Naval supone más de 3 millones de $\mathrm{m}^{3} / \mathrm{año}$, consumidos por la dotación de marinería y el suministro de buques. Por su parte, las citadas entidades industriales repercuten decisivamente en la base productiva y en el empleo, aunque es de notar que el gasto en uso industrial se encuentra muy estabilizado. Aunque en la actualidad, los planes de reconversión industrial, en el marco del desarrollo regional, están impulsando nuevas implantaciones fabriles, que obligan cuando menos a garantizarlos niveles de abastecimiento y prever incrementos hacia el futuro a lo que también contribuye el relanzamiento de las empresas de REPSOL (R. Butano y Enagás). En cuanto al ritmo de crecimiento de la ciudad, entre 1970 y 1986 resulta escaso (de 146.904 habitantes a 168.809), pero son muy favorables las expectativas para el crecimiento del espacio turístico citado y, por sí mismas, justifican una demanda creciente de caudales.

La desproporción observada en el nivel de gasto de Molina del Segura responde a un único factor, la modernización y tecnificación de la industria conservera, en relación con las 


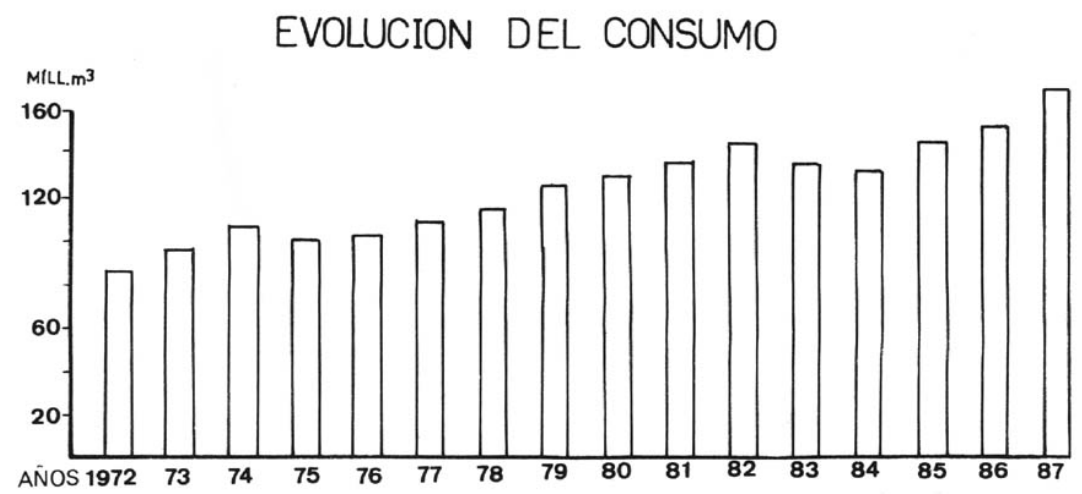

producciones agrarias de la Vega del Segura, y la implantación novedosa de industrias químicas, lo que justifica un singular proceso de expansión urbana y demográfica (ha pasado de 16.308 habitantes en 1960 a 34.913 en 1986). Son las industrias, por sus especiales características, el factor que determina la gran demanda de agua (4’7 millones de $\mathrm{m}^{3}$, en 1987), muy superior a la cantidad requerida en otros procesos fabriles de la región y que además debe reunir unas condiciones mínimas de calidad, al tratarse, en gran parte, de industria alimentaria.

Las industrias conserveras justifican sólo en una pequeña parte el elevado nivel de gasto detectado en la capital murciana, a lo que también contribuye el modelo urbano, con un notable contingente de población diseminada o en pequeñas pedanías a las que llega el agua potable. No menos importante es el gasto para uso público, al no contar la ciudad con caudales reciclados de la red de saneamiento que se utilizarían en el riego de parques y jardines, calles, etc. En 1987, Murcia alcanzó la mayor cifra de consumo, con $35^{\prime} 8$ millones de $\mathrm{m}^{3}$, en el marco de una tendencia constante de crecimiento (la población ha pasado de 243.759 habitantes en 1970 a 309.504 en 1986), reforzada por el papel de capital regional. Ha influido decisivamente la expansión del tejido urbano, mediante la configuración de nuevos polígonos residenciales, al tiempo que se produce la renovación del caserío en el centro tradicional; este último hecho supone una mejor dotación de servicios urbanos en las unidades de vivienda, lo que se traduce de inmediato en el incremento del uso del agua. No menos notable es la repercusión de los polígonos industriales ubicados en Espinardo y Sangonera. Sin embargo, el dato más sorprendente es el de la pérdida de agua en la red del núcleo urbano, cifrada en un porcentaje excesivamente elevado (el rendimiento medio del agua consumida es del 56\%), por el envejecimiento de las infraestructuras, lo que contribuiría también a explicar el citado desajuste entre población y consumo. En cualquier caso, considerando que se pueden obviar las deficiencias técnicas, es necesario considerar el ritmo de crecimiento, con el fin de establecer las oportunas previsiones.

La capital alicantina ha experimentado uno de los mayores crecimientos del gasto de agua dentro de la MCT, pasando de 13'9 millones de $\mathrm{m}^{3}$, en 1975 a 25'8 en 1987, cifra que incluye 
el agua extraña, procedente de los pozos de Villena adquiridos por la empresa municipal de aguas. Este incremento del consumo guarda estrecha relación con el crecimiento del núcleo urbano, con función de centro comercial y de servicios, que pasa de 184.716 habitantes en 1970 a 265.543 en 1986. Pero también depende estrechamente del auge de la actividad turística en la franja costera del municipio, que ha contribuido al desarrollo de los servicios y del subsector de la construcción y afines. De tal manera que, por lo que atañe a previsiones de crecimiento, se ha relanzado de nuevo el proceso de construcción (PAU 4 y 5 de la Playa de San Juan, Agua Amarga), lo que hace prever un constante aumento de la demanda de agua.

Más atenuado se encuentra el crecimiento de Elche, que se vio seriamente afectado por la crisis industrial, aunque el gasto de 4'1 mill. de m., lo sitúa en un lugar prioritario dentro de la MCT, cifra que incluye en torno al 14\% de agua extraña, procedente de pozos de la tierra de Crevillente y aledaños (Los Suizos). La industria del calzado no repercute en el consumo de agua del modo indicado para la conservera, mientras que la urbanización turística del litoral (Arenales) dista considerablemente de las proporciones habituales en municipios costeros. Un dato relevante, en este sentido, es que el PGOU vigente ha supuesto la pérdida de suelo calificado por el anterior planeamiento, reduciéndose las perspectivas de incremento de los asentamientos turístico-residenciales.

Muy por debajo de los niveles de gasto indicados, aunque bien situadas en el conjunto de la MCT, están dos ciudades, con rango de capital subregional en el caso de Lorca y comarcal en el de Orihuela (muy discutido en los últimos años por el crecimiento desbordante de Torrevieja). La primera combina el nivel de prestación de servicios con la vocación rural de la comarca, en proceso de modernización con la expansión del regadío y los nuevos cultivos, y algunas industrias chacineras; en conjunto se entiende el crecimiento reciente del núcleo (60.627 habitantes en 1981 y 66.880 en 1986), cuyas perspectivas son favorables, sobre todo cuando la mejora de la red viaria facilite la accesibilidad y la prestación de servicios, de manera que los 6’7 mill. de $\mathrm{m}$, tenderán a incrementarse.

Mucho menos favorables son las perspectivas de crecimiento para Orihuela, cuyas mejores posibilidades cara al futuro se encuentran en la zona costera, entre La Dehesa de Campoamor y Punta Prima, en consonancia con el proceso de construcción de alojamientos turísticos. Esta zona se abastecía con aguas hipógeas, hasta que el comentado desajuste entre población y caudales ha obligado al recurso a las aguas del trasvase, que llegan a esta franja a través del Nuevo Canal de Cartagena. La misma infraestructura abastece al nuevo municipio de El Pilar de La Horadada, segregado recientemente de Orihuela, con unos 8.000 habitantes de hecho, y cuyo gasto aparece incluido hasta 1987 en los 5'4 mill. de $\mathrm{m}$, facturados a dicha ciudad. Por tanto, la pérdida del núcleo de El Pilar y sus urbanizaciones costeras (La Torre y Las Mil Palmeras) se verá compensada por la incorporación al abastecimiento de Orihuela del resto de su litoral, lo que hace prever para este municipio un crecimiento constante de las necesidades de agua.

\section{Recursos y modelo de desarrollo económico-territorial}

El problema del consumo de agua en el ámbito de la MCT no puede desprenderse de su contexto ecológico y técnico, es decir, las propias condiciones climáticas, que dan como resultado la característica xerotermia, y la necesidad de acometer grandes y costosas infra- 
Cuadro II

FACTURACIÓN MENSUAL EN M ${ }^{3}$.

\begin{tabular}{llll}
\hline Enero & 12.434 .114 & Julio & 15.821 .323 \\
Febrero & 11.494 .504 & Agosto & 17.183 .461 \\
Marzo & 13.157 .911 & Septiembre & 15.743 .108 \\
Abril & 12.367 .364 & Octubre & 14.180 .298 \\
Mayo & 13.804 .984 & Noviembre & 12.783 .532 \\
Junio & 14.619 .148 & Diciembre & 13.157 .518 \\
\hline
\end{tabular}

AGUA FACTURADA POR LA MANCOMUNIDAD DE LOS CANALES DEL TAIBILLA EN EL AÑO 1987

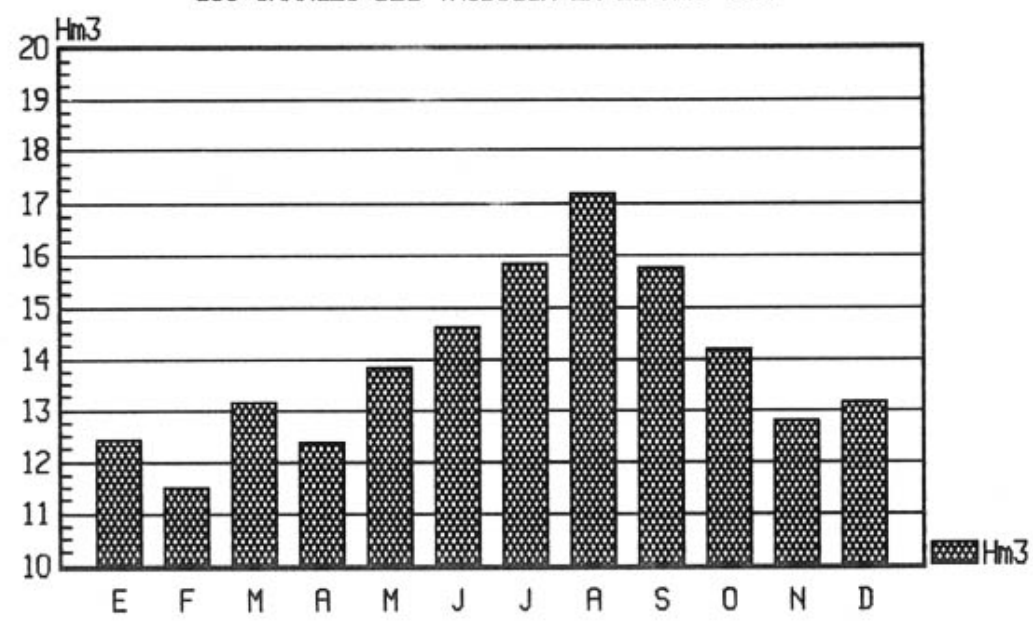

estructuras para garantizar el abastecimiento, cuando faltan recursos autóctonos que permitan mantener el actual ritmo de crecimiento, sobre todo cuando las áreas de mayor consumo, coincidentes con las de mayor trascendencia económica, son las que acusan un déficit superior, al combinarse el máximo gasto con la indigencia de recursos propios. Hasta tal punto se plantea el problema que las dotaciones de agua se convierten en uno de los principales recursos afectados al desarrollo regional, que actúa como condicionante y limitante en los procesos de puesta en valor del territorio. Cabe entonces preguntarse, a tenor de la tipología de municipios comentada, si se está ante una puesta en valor desequilibrada de los recursos. Es cierto que los recursos se están destinando a las áreas con mayor riqueza o, en todo caso, con un potencial más alto, es decir, a aquellos lugares donde se rentabilizan, desde una perspectiva exclusivamente económica. 
Frente a los municipios del interior, de base predominantemente rural, con bajo nivel de suministro de agua, se ha señalado la evolución de las capitales y núcleos industriales y de los municipios turísticos. Al grupo de las mayores ciudades, algunas con base industrial, corresponden los mayores niveles de consumo dentro de la MCT; Murcia supone el $21{ }^{\prime} 4 \%$ del total de agua facturada y Alicante el $15,5 \%$, mientras que el conjunto de las mayores ciudades concentra en torno al $60 \%$ del total del gasto de agua. El crecimiento de este grupo es constante, en relación con su entidad, por lo que la única compensación técnica al elevado nivel de consumo se deberá centrar en la depuración de las aguas residuales.

No obstante, el problema que ha empezado a causar desequilibrios en la estructura de la MCT y en el modelo económico-territorial vigente es el desbordamiento del consumo de la franja litoral, basado en una idea de crecimiento ilimitado, mediante la venta de terrenos y construcción de alojamientos turísticos.

A tenor del incremento en el número de viviendas construidas, sería oportuno plantear el límite que los recursos hídricos suponen al proceso de construcción de alojamientos turísticos. Pero el planeamiento urbanístico no ha tenido en consideración el carácter frágil y limitante de los recursos acuíferos a la hora de calificar suelo con fines residenciales. Basta señalar que la capacidad de población prevista para los municipios de Santa Pola, Guardamar, Torrevieja, El Pilar de La Horadada y litoral de Elche y de Orihuela alcanza la cifra de 600.000 habitantes, a pesar de las limitaciones existentes en la actualidad, lo que demuestra que el suministro de agua se pospone o se improvisa una vez ejecutadas las actuaciones urbanísticas, mediante compromisos políticos, cuando lo lógico sería garantizar el abastecimiento y ajustar el crecimiento urbano-turístico al mismo ${ }^{7}$.

Esta misma tendencia orientada a la configuración de nuevos asentamientos turísticos, al margen de la planificación de los recursos acuíferos, aparece en el litoral murciano y en la Costa del Sol, como característica inherente al impulso de las inversiones en promoción y construcción inmobiliaria, dependiente en gran medida del capital extranjero, en cuya cabeza se sitúan las provincias de Málaga y Alicante. Se trata de una nueva fase marcada por el negocio inmobiliario, que trasciende el estricto marco de las actividades turísticas y que impregna todo el contexto económico-territorial.

Así se pone de manifiesto con los nuevos proyectos de urbanización en auge, que representan la orientación o el intento de captar demandas más selectivas, mediante la incorporación a los nuevos asentamientos de elementos de atracción tales como campos de golf, lagos artificiales, parques acuáticos, atracciones, hipódromos, etc. En todos ellos el agua está presente como factor esencial y abundante, en contraste con la xerotermia característica de este dominio bioclimático. Los niveles de consumo dan idea del despilfarro que supone la utilización del agua en relación con las actividades de ocio. De este modo, los grupos económicos actuantes en la producción del espacio turístico, con grandes posibilidades financieras, consiguen obviar el problema de la escasez de recursos, resolviendo a su favor la competencia con otros sectores de usuarios, esencialmente los vinculados a la actividad agraria.

Si se definen prioridades cuando la demanda excede a las posibilidades se producen conflictos; son los criterios de rentabilidad, centrados en un objetivo determinado, los que se

7 VERA REBOLLO, J.F., "Los recursos hídricos como factor condicionante del desarrollo turístico en el litoral alicantino", ap Demanda y Economía. 
anteponen a la gestión ${ }^{8}$. Se impone así un criterio puramente economicista en el uso y rentabilización del agua, al margen de las necesarias consideraciones sociales y de orientación hacia un desarrollo equilibrado y con carácter de continuidad. No obstante, para la propia administración, los nuevos macroproyectos de urbanización representan una cualificación del producto turístico y se interpretan como una alternativa a la oferta tradicional, que denota evidentes síntomas de crisis. Pero la utilización del agua como lujo implica unos costes privativos para el resto de usuarios, que amenaza la supervivencia de espacios de regadío, que presentan hoy en día excelentes perspectivas de futuro.

Frente a ello es necesario hacer una consideración sobre las medidas de ahorro, ya que en la actividad agraria, frente a este despilfarro, los sistemas de cultivo tienden a adecuarse a la introducción de los procedimientos de riego localizado, que se traducen en un gasto considerablemente menor respecto a los métodos tradicionales. Mientras tanto, en los espacios turísticos se eleva el consumo medio de agua por turista.

La única solución posible a tales desajustes deriva de la opción por una vía cualitativa del desarrollo, que consistiría en limitar el ritmo de construcción de alojamientos y en una diversificación, mejora y cualificación del actual producto turístico, cuya masificación y pérdida de calidad amenazan seriamente la idea de un desarrollo equilibrado. En pocos años la expansión de los núcleos marítimos ha consolidado una nueva jerarquía de centros dominantes, frente al interior rural, que se beneficia del mercado de trabajo posibilitado por la estructura productiva de la actividad turística.

Otras soluciones al problema de los desequilibrios derivan específicamente de los criterios de compensación, entendiendo una perspectiva integrada de las disponibilidades acuíferas en el desarrollo regional, en tanto que son un factor esencial para entender la ordenación del territorio.

\subsection{Necesidad de una gestión integrada}

Se puede señalar, sin ninguna duda, que el crecimiento urbano-turístico del SE peninsular ha estado posibilitado, al menos hasta la fecha, por un sistema comunitario que suministra el agua potable sin tensiones ni estrangulamientos. Pero el techo alcanzado por los volúmenes y el incesante ritmo progresivo de la demanda frente a la disponibilidad de recursos y a los conflictos de competencias, hacen aconsejable la opción por un sistema más racional, orientado tanto al abastecimiento como a la depuración y saneamiento; a este último aspecto no se ha orientado la MCT, a diferencia de otras empresas públicas con fines similares (el Canal de Isabel II en Madrid, p.e.). Es cierto que el sistema constituye un modelo en cuanto a búsqueda de recursos, abastecimiento, depuración e infraestructura, pero el saneamiento ha quedado en manos de los ayuntamientos que, con fondos propios y de otros organismos, han puesto en marcha depuradoras para aguas residuales, que permiten reciclar un volumen notable de caudal, aprovechado en espacios agrícolas de la comarca respectiva. Conviene destacar la estación depuradora de aguas residuales de Alicante y la de Torrevieja, que han permitido incluso la transformación de secanos en nuevos espacios de regadío en el valle del

8 BETHEMONT, J., Ob cit. pp. 181 y 183. 


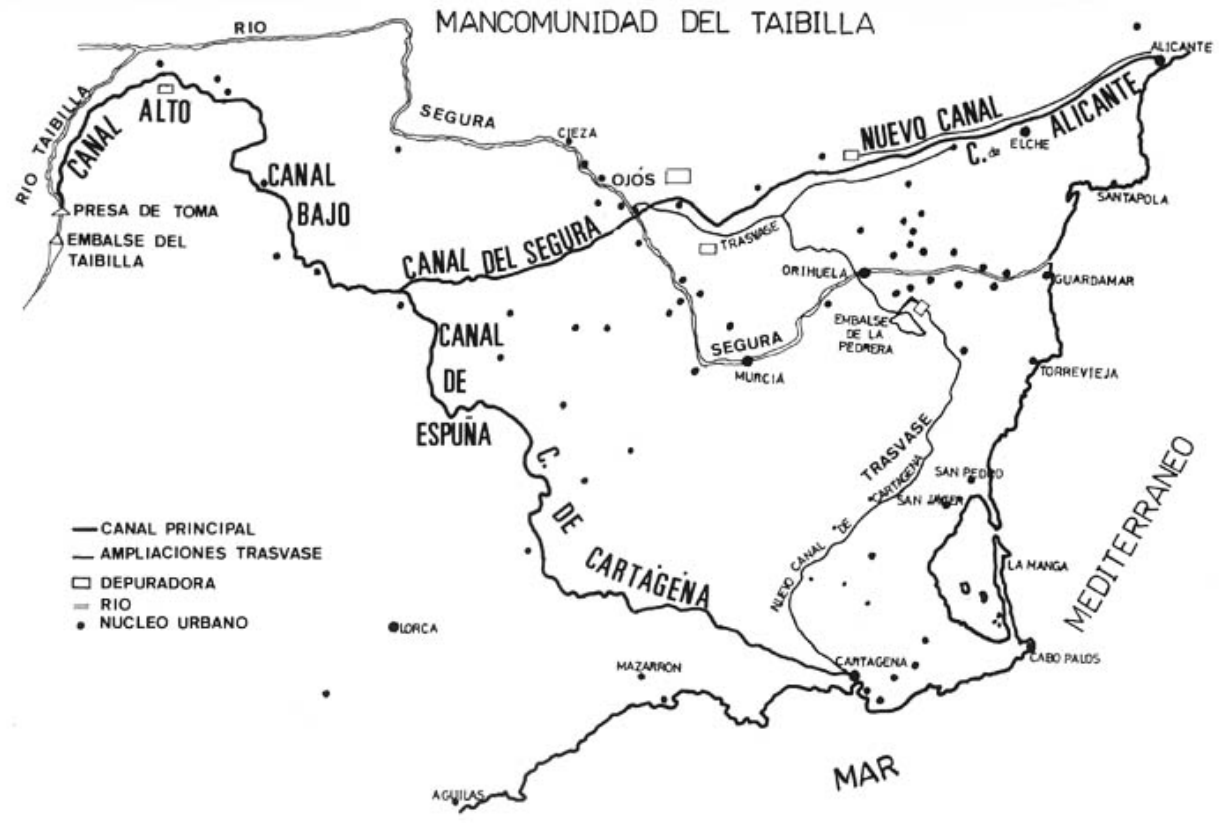

Red principal de los canales de distribución de aguas y localización de las depuradoras. 
Vinalopó y en la laguna salada, respectivamente. Pero se trata de actuaciones puntuales, de manera que sólo un intento globalizador, a escala de toda la MCT, posibilitará la realización del ciclo integral del agua.

\section{Conclusión}

Ante tales conflictos por el uso del agua deben plantearse soluciones que derivan de una nueva fillosofía del modelo de desarrollo económico-territorial, considerando que el incremento del gasto de agua que determina el proceso de crecimiento de los grandes centros urbanos y de los municipios turísticos, se hace básicamente a costa de los recursos del trasvase y, por ende, el mayor consumo urbano repercute en una merma de las disponibilidades para riego. Se trata, por tanto, de conflictos espaciales y sectoriales que obligan a una adecuada coordinación del desarrollo sectorial con la política económica en su conjunto, entendida en el marco del desarrollo regional.

En esta línea, se han materializado los instrumentos limitantes, mediante la aprobación de leyes que, como en el caso de la nueva Ley de Ordenación del Territorio de la Comunidad Valenciana, contemplan la necesidad de resolver y garantizar el abastecimiento de aguas, como paso previo a la urbanización. Naturalmente, y a tenor del nuevo despegue económico que afecta al SE peninsular, auspiciado por las administraciones locales y autonómicas, ello tiene una doble lectura, por cuanto justificará la puesta en marcha de nuevos trasvases y la prioridad más absoluta para el uso urbano y turístico del agua. 